\title{
Using Technology in EFL in Saudi Arabia
}

\author{
Yousef Hamad Al-Maini \\ College of Languages and Translation, Saudi Arabia
}

\begin{abstract}
The purpose of this paper is to highlight some of the issues facing a developing country in implementing computer technology in subject teaching, specifically English as a Foreign Language $(E F L)$. The observation made here were derived in the context of a wider study of processes and influencing factors in the teaching of EFL at the secondary school level in Saudi Arabia. A case study methodology was adopted, focusing on a typical state secondary school in Al-Qaseem Arae. Data were gathered primarily by means of classroom observations and semi-structured interviews with the headteacher, teachers and students in the case study school. Schools were at an early stage of technology development, characterized by the availability of computer laboratories for the teaching of Computer Studies, but a lack of classroom computers, language laboratories or other means of integrating computers into subject teaching. Access and availability were clearly linked to funding issues and uncertainty as to whose responsibility it was to provide equipment. Teacher resistance to computer technology was linked to curriculum pressures and lack of training. These factors must be addressed, if the benefits of computer integration are to be realised.
\end{abstract}

\section{Introduction}

Our world is witnessing a technological revolution in the field of information and communication and communication. This article considers the potential of this new technology for assisting teaching and learning English as a foreign language (EFL) in state-run boys' secondary schools in Saudi Arabia, based on the findings of a case study exploration of attitudes and processes currently affecting EFL in Al-Qaseem Area. It sheds light on some difficulties facing the use of computers in these schools and how the headteachers and teachers are responding to these difficulties. It concludes with the view that technology can no longer be ignored.

\section{The Present Study: Context, Methods and Participants}

What follows is based on an interpretive, qualitative study carried out in Al-Qaseem Area in Saudi Arabia, to explore the teaching of English as a foreign language. One of the issues investigated was the availability and use of educational technology resources, and how this influences teaching and learning. An intensive case study was carried out in one state secondary school containing 200 students, age 15-18 years, distributed in three years or grades and 10 classes. Class sizes varied from 25 to 30 students. The headteacher, all four English teachers and more than 60 students were interviewed, and 18 classroom observations carried out, covering all three years of study. In addition to the main case study, visits were made to two other secondary schools in the same area and interviews conducted with a further four English teachers.

\section{The Role of Computer Technology in EFL}

In Britain, a collaborative effort on the part of many language teachers and schools in the late 60s and early $70 \mathrm{~s}$ led to the so-called situational teaching, i.e. "syllabuses and methods [based on] 'relevant' topics and situations, e.g. shopping, hobbies or exchange visits" (Mitchell [5]). A few years later, it was found that "purely situational syllabuses were not the whole answer". Something more was needed. This led to the rise of the 'functional syllabus model'. It too failed to attain full satisfaction, leading to the rise of the interactional approach.

The communicative approach to teaching claims that if second language acquisition recapitulates first language acquisition, or does so for the most part, then it is obvious that the teaching of second language should benefit from the same procedures and strategies exhibited by both L1 acquirers and natural L2 acquirers. The cornerstone of the communicative theory is that the learner has to use the target language as a medium of interaction, consistent with social constructivist thinking. "[The] notion of direct rather than delayed practice of communicative acts is central to most CLT interpretations" (Richards and Rodgers [6]). The learning or acquisition of rules "arises from constant practice in the communication" (Little et al., [4]), activities involving both listening and speaking at the same time.

Within such an approach, computer technology potentially has immense value, both as a source of "comprehensible input" (Krashen and Terrell [3]) and as a medium for shaping and disseminating output which promotes fluency, encourages syntactic 
language processing and affords students opportunities to receive feedback from others.

The Internet has enormous potential in language teaching, as a resource for EFL, and as a means for communication between the EFL communities. It provides realistic, authentic native-speaker models of the language (text) and on-line radio broadcasts (audio). The Internet also offers language-learning curricula. Teachers can find information and materials on all kinds of subject matter, lesson plans, supplemental activities and many other various forms of assistance. Students can find information in English on their specific subjects (ESP). For example, students in the scientific stream can find sites dedicated exclusively to English for science exclusively, full of exercises, tasks, etc.

Moreover, since language is an evolving entity, the Internet, with its enormous growth rate, allows easy updating of materials and information and thus, provides EL teachers and students with up-to-theminute language and knowledge.

The Internet, unlike other sources of information (e.g. books, magazines, video tapes), with the help of other applications such as word processors, allows not only the retrieval of information but also the manipulation of almost every bit of it. This feature is a great help in preparing classroom presentations. For instance, the teacher can use modified extracts from an on-line encyclopaedia to make a quiz or a reading passage.

The Internet is a powerful tool for communication between teachers and students, among teachers and among students. In the Saudi context, it offers a cheap and convenient way of communication. They can make friends with other native speakers without the need to travel abroad. They can have Englishspeaking 'keypal' friends with whom to practise their writing and reading skills, just like having normal penpal friends, though in a faster and cheaper way. For example, Mohammed told me that he is still in contact with his British friends by e-mail and messenger, and this has improved his English skills.

Moreover, the computer with its multimedia technology offers opportunities for successful collaborative learning and teamwork in small groups (SIIA report [7]). It also promotes interactive language teaching at the highest level (Felix [2]). It is capable now of providing virtual learning settings such as classrooms and laboratories. It allows real interaction between the teacher and students at different places just as in a real classroom.

This potential, however, has yet to be realised in Saudi Arabia, for a variety of reasons: a rigid, overcrowded curriculum, lack of resources, and inadequate teacher preparation-particularly as in Saudi a graduate in any subject is considered automatically qualified to teach, without any specific training in pedagogy.
Contemporary EFL textbooks espouse the communicative approach. However, my observations suggest that few teachers are able to cope with the 'challenging' directions given to them in the Teacher’s Book [8]. The prevailing and preferred methods are the traditional ones, mainly the grammar translation method. The only use of communicative language teaching I observed was by a teacher in a school other than the case study school, who had a specially equipped, privately funded language room.

In most schools, the textbook is the sole reference for the teacher and students and is very dull. The class is teacher-centred and the students are largely passive, with little chance to generate their own oral or written output to develop their linguistic and communicative skills. Activities and tasks are very limited, driven by an assessment system which relies heavily on memorization of grammar rules and formulaic sentence structures.

A major reason for the popularity in foreign language contexts similar to the Saudi context of what Cook [1] calls "the academic style", i.e. grammar-translation and audio-lingual methods, is that they provide "a clear framework for teachers to work within. Teachers always know what they are supposed to be doing, unlike more flexible or improvisational styles” (Cook, [). This is exactly what I meant when I argued above that the communicative approach to the teaching of L2/FL may appear 'too challenging' to some EFL teachers. Nevertheless, there are signs of change, as the following experiences from my fieldwork demonstrate.

\section{The student perspective}

In considering whether to deploy the new technologies, teachers will take account of the specific learning that students achieve, and the motivation of students who use the new technologies for learning. New technologies have the power to stimulate the development of intellectual skills such as reasoning and problem solving ability, learning how to learn, and creativity (US Congress, Office of Technology Assessment [9]).

My fieldwork in Al-Qaseem Area, Saudi Arabia, provided evidence that new technologies can develop students' interest in learning activities and to lead them to devote more time and attention to these activities than in regular classes. Moreover, they increase their confidence in their abilities. This in part the spontaneously receptive attitude that a large number of them adopt toward any activity in which technology plays a role. For instance, a student expressed the view that it would be helpful to use the school's ICT laboratory for English language, and suggested that the teacher could guide them to the English language web sites. He added: 
"We ask the administration in our school to do that as soon as possible. I believe that if we go to the information lab once a week and try to find out a lot about the target language [i.e. English], our language will be better".

This would enable students to use the Internet in that laboratory to serve as a medium for experiences and presenting creative work. While students can peruse the information on the Net, they can also use it as a platform for their own work such as writing composition, or speaking.

A number of students similarly had the idea that their learning would be facilitated if they had the opportunity to use a language laboratory. For example, Yassir said that "Labs will make you love the subject and that will force you to learn". Hamad expressed the same idea, placing language laboratories in the context of a more varied and interesting approach to language teaching generally. He said:

"I think that using other teaching aids such as language labs would be more enjoyable, and would help us to grasp the language more effectively”.

ICT is potentially valuable for learning, but particularly for listening skills, and through this, for pronunciation skills. It provides for accurate listening and controlled pronunciation with model voices, as well as helping students to overcome their shyness and giving them confidence to experiment with the language. In many cases, however, ICT is still infrequently used or even unavailable. In AlQaseem area, there are teachers who are willing and able to use it, and their EFL teaching is enriched as a result, but as yet these are mainly the privately funded efforts of a few pioneering individuals.

\section{Is teacher's Support necessary?}

Teachers need to provide sufficient support to their students, to prevent their being overwhelmed by difficulties. This kind of support can take numerous forms: creating detailed handouts that students can refer to when class is finished and the teacher's personal help is not accessible; building technology training sessions into the class schedule, working with the computer centre to set up log-on systems and other procedures; assigning students to work in pairs or group, both in and out of the lab, so that they can provide assistance to each other; they can also provide details to the students about how and when they can get assistance from technology specialists outside the class; and being available to help students at times when they are most likely to need it.
Far from providing such support, many Saudi teachers, however, are resisting technology implementations. During my discussion with one of the English teachers, Ahmed, the possibility of taking students to the Learning Centre in the school was raised. Ahmed reported that he did not think that this would lead to any improvement in students' performance.

The benefits of using modern technology in teaching English were clearly recognised also by Sami, another of the English teacher whom I interviewed. Sami had initiated what he called an 'English Room' in his school. That room contained a computer and data projector, which Sami himself had paid for. Observing an English lesson in that room was an enjoyable experience, with all students fully engaged and participating actively. Sami told me that the project arose out of his awareness that students were bored with the traditional way of teaching.

He had obtained permission from the headteacher to install the equipment in a spare room, and he took care of the maintenance by himself. The headteacher of Sami's school expressed his support for Sami's initiative and said, "If any English teacher asked me to provide him a room as I did with Sami, I would do that and write to the Educational District to support him”.

Sami's experience and attitude make an interesting contrast with the views of Ahmed. Both teachers were Saudi, and had trained under the Saudi system of teacher preparation. Thus, within the same cultural context and among teachers of similar background, there were very different attitudes in relation to the use of educational technology. Sami's initiative is also at odds with a view frequently expressed by teachers I interviewed, that it is "forbidden" for teachers to bring extra resources. One explanation may lie in the comment of one teacher that it is acceptable to bring audio-visual resources, because the Ministry does not provide them. In other words, he appeared to make a distinction between those aids, such as flash-cards and text-books, which the authority committed itself to provide and which had presumably been officially approved as sufficient and appropriate (and therefore not to be supplemented or substituted) and those which the Ministry did not undertake to provide perhaps for financial reasons. It could also be argued that a projector, for example, is ideologically neutral; it is merely one way of delivering content. Whereas the use of computers and access to the web can bring instant exposure to Western values, the use of other equipment is more easily mediated by the teacher. The teacher has control over the materials used and as the examples cited here show, the content delivered is still that provided by the Ministry, i.e. the textbook. It is possible, too, that there were institutional differences in the schools, such as the 
support of the headteacher, the availability of a room not timetabled for other purposes, or the general professional culture among the English teachers, which contributed to the different practices of the teachers.

\section{Conclusion}

The new technologies present provocative opportunities for improving education and possibly making it less expensive. What is clear, however, is that change will happen and it is important to keep in mind that the way we teach today is neither the only nor the best way. Lectures and discussion, combined with practice in the form of homework, laboratory experiments, and similar exercises, grading, and examinations, have been and still are a very effective method of educating large numbers of students.

I also suggest that, in order to maximize the resources available to schools, cooperation should be encouraged so that schools share and exchange resources. This would not only benefit the students, but might help to foster collegial relations and contribute in the development of a professional culture in Saudi Arabia.

\section{References}

[1] Cook, V. 1991. Second Language and Language Teaching. New York: Routledge, Chapman and Hall.

[2] Felix, U. (1998). "Virtual language learning, finding the gems amongst the pebbles", Melbourne: Language Australia Ltd.

[3] Krashen, S.D. \& Terrell, T.D. (1983). The Natural Approach. Oxford: Pergamon.

[4] Little, D, Devitt, S. \& D. Singleton. 1994. 'The communicative approach and authentic texts' in A. Swarbrick (ed.). Teaching Modern Language.

London: Routledge and Open University Press.

[5] Mitchell, R. 1994. 'The communicative approach to language teaching'. in A. Swarbrick (ed.). Teaching Modern Language. London: Routledge in association with the Open University Press. Available on-line at http:eprints.soton.ac.uk

[6] Richards, J.C. and Rodgers. 1986. Approaches and Methods in Language Teaching, Cambridge: Cambridge University Press.

[7] SIIA report 2000. 'The Software and Information Industry Association', http://www.siia.net.

[8] Teacher's Book. 1994. Teacher's Book. Riyadh: Ministry of Education, Saudi Arabia.

[9] US Congress, Office of Technology Assessment. 1995. Teachers and Technology: Making the Connection. Washington, D.C.: Government Printing Office. 